\title{
Article \\ Differential MMP-14 Targeting by Lumican-Derived Peptides Unraveled by In Silico Approach
}

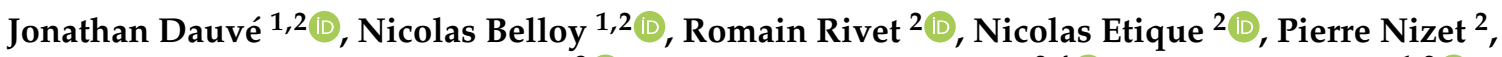

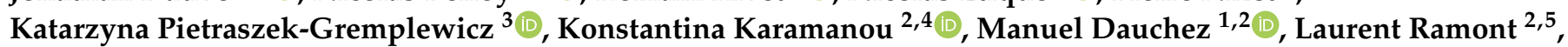 \\ Stéphane Brézillon ${ }^{2}\left(\mathbb{B}\right.$ and Stéphanie Baud ${ }^{1,2, *(1)}$
}

1 P3M, Multi-Scale Molecular Modeling Platform, Université de Reims Champagne Ardenne, 51097 Reims, France; Jonathan.Dauve@ico.unicancer.fr (J.D.); nicolas.belloy@univ-reims.fr (N.B.); manuel.dauchez@univ-reims.fr (M.D.)

2 CNRS UMR 7369, Matrice Extracellulaire et Dynamique Cellulaire (MEDyC), Université de Reims Champagne Ardenne, 51095 Reims, France; romain.rivet@univ-reims.fr (R.R.); nicolas.etique@univ-reims.fr (N.E.); pierre.nizet@univ-reims.fr (P.N.); kon.karamanou@gmail.com (K.K.); lramont@chu-reims.fr (L.R.); stephane.brezillon@univ-reims.fr (S.B.)

3 Department of Cell Pathology, Faculty of Biotechnology, University of Wroclaw, Joliot-Curie 14a, 50-383 Wroclaw, Poland; katarzyna.pietraszek-gremplewicz@uwr.edu.pl

4 Biochemistry, Biochemical Analysis \& Matrix Pathobiology Research Group, Laboratory of Biochemistry, Department of Chemistry, University of Patras, 26110 Patras, Greece

5 CHU Reims, Service Biochimie Pharmacologie-Toxicologie, 51092 Reims, France

* Correspondence: stephanie.baud@univ-reims.fr

check for
updates

Citation: Dauvé, J.; Belloy, N.; Rivet, R.; Etique, N.; Nizet, P.;

Pietraszek-Gremplewicz, K.;

Karamanou, K.; Dauchez, M.;

Ramont, L.; Brézillon, S.; et al.

Differential MMP-14 Targeting by

Lumican-Derived Peptides

Unraveled by In Silico Approach.

Cancers 2021, 13, 4930. https://

doi.org/10.3390/cancers13194930

Academic Editor: Brian Gabrielli

Received: 3 September 2021

Accepted: 27 September 2021

Published: 30 September 2021

Publisher's Note: MDPI stays neutral with regard to jurisdictional claims in published maps and institutional affiliations.

Copyright: (C) 2021 by the authors. Licensee MDPI, Basel, Switzerland. This article is an open access article distributed under the terms and conditions of the Creative Commons Attribution (CC BY) license (https:/ / creativecommons.org/licenses/by/ $4.0 /)$.
Simple Summary: This work aimed to investigate the interactions of lumican-derived peptides and MMP-14. An in silico approach unraveled key residues in the amino acid sequence of MMP-14 interacting with the Small Leucine-Rich Proteoglycan (SLRP) lumican-derived peptides. The in silico docking analysis demonstrated that the interaction of a cyclic lumican-derived peptide (L9Mc, 12 amino acids) with MMP-14 was preferential with the MT-Loop domain of MMP-14 while the linear lumican-derived peptide (lumcorin, 17 amino acids) interacted more with the catalytic site. L9Mc significantly inhibited the migration of murine B16F1 but not human HT-144 melanoma cells and the activity of MMP-14 but with less efficacy than lumican and lumcorin. This result led us to investigate the effect of L9Mc on cell proliferation, which is independent of MMP-14 activity. L9Mc significantly inhibited the proliferation of B16F1 but not HT-144 melanoma cells in vitro and primary melanoma tumor growth. Altogether, the biological assays validated the prediction of the in silico study.

Abstract: Lumican, a small leucine-rich proteoglycan (SLRP) of the extracellular matrix (ECM), displays anti-tumor properties through its direct interaction with MMP-14. Lumican-derived peptides, such as lumcorin (17 amino acids) or L9M (10 amino acids), are able to inhibit the proteolytic activity of MMP-14 and melanoma progression. This work aimed to visualize the interactions of lumican-derived peptides and MMP-14. Molecular modeling was used to characterize the interactions between lumican-derived peptides, such as lumcorin, L9M, and cyclic L9M (L9Mc, 12 amino acids), and MMP-14. The interaction of L9Mc with MMP-14 was preferential with the MT-Loop domain while lumcorin interacted more with the catalytic site. Key residues in the MMP-14 amino acid sequence were highlighted for the interaction between the inhibitory SLRP-derived peptides and MMP-14. In order to validate the in silico data, MMP-14 activity and migration assays were performed using murine B16F1 and human HT-144 melanoma cells. In contrast to the HT-144 melanoma cell line, L9Mc significantly inhibited the migration of B16F1 cells and the activity of MMP-14 but with less efficacy than lumican and lumcorin. L9Mc significantly inhibited the proliferation of B16F1 but not of HT-144 cells in vitro and primary melanoma tumor growth in vivo. Thus, the site of interaction between the domains of MMP-14 and lumcorin or L9Mc were different, which might explain the differences in the inhibitory effect of MMP-14 activity. Altogether, the biological assays validated the prediction of the in silico study. Possible and feasible improvements include molecular dynamics results. 
Keywords: MMP-14; lumican; in silico approach; molecular docking; dynamics; melanoma

\section{Introduction}

The extracellular matrix (ECM) is formed of a complex network of macromolecules, such as proteins, glycoproteins, and proteoglycans. This diversity is one of the main characteristics of the ECM. This highly ordered matrix constitutes an architectural support through which cells and, in particular, invasive melanocytes will migrate. ECM is also a reservoir of cellular signals, which can be produced by the surrounding cells or via the degradation of ECM compounds into peptide fragments endowed with biological activity called matrikines [1-3].

Matrix metalloproteinases (MMPs) are composed of a family of $\mathrm{Zn}^{2+}$-dependent enzymes able to cleave ECM proteins in normal and pathological conditions [4]. MMPs are overexpressed in various human malignancies and contribute to tumor invasion and metastasis by degrading ECM components [4-6]. Particularly, MMP-2, MMP-7, MMP-9, and MMP-14 have been associated with tumor invasion and metastasis by their capacity to degrade the ECM [7]. MMP-14, a transmembrane matrix metalloproteinase (MT-MMP), is characterized by a C-terminal domain allowing the anchoring of the protein to the membrane, an MT-Loop being involved in the activation of proMMP-2, and a catalytic domain where a zinc ion is found in the catalytic site, allowing its enzymatic activity. Among the different proteins expressed in the ECM, tissue inhibitors of metalloproteinases (TIMPs) inhibit the activity of MMPs. TIMP-1 was shown to be unable to prevent MMP-14 processing of wild-type progelatinase A in contrast to TIMP-2 and TIMP-3 [8,9]. TIMP-1 is an extremely poor inhibitor of MMP-14 while TIMP-2 and TIMP-3 bind more rapidly to the catalytic domain of MMP-14 than to the one of gelatinase A [10].

Lumican belongs to the family of small leucine-rich proteoglycans (SLRPs) that includes decorin, biglycan, and fibromodulin, among others [11,12]. Lumican is the major keratan sulfate proteoglycan of the corneal stroma [13-18], but it is also expressed in other tissues, such as skin [19] and cartilage [20]. Lumican has been identified as a substrate of MMP-14 [7]. Similarly, the degradation of decorin by MMP-14 has been previously described [21]. Only MMP-13 is capable of efficiently cleaving fibromodulin and biglycan [22,23] and has a poor effect on lumican and decorin cleavage [23]. Thus, although they share structural features [24,25], these SLRPs present different affinities for MMP-14. Surface Plasmon Resonance (SPR) binding assays confirmed the direct interaction of the catalytic domain of MMP-14 with lumican with moderate affinity (KD \# $275 \mathrm{nM}$ ), which leads to complete blocking of the activity. Lumican can act also as a competitive inhibitor [26]. Lumican was shown to protect collagen against MMP-14 proteolysis, leading to inhibition of tumor progression. Despite the fact that lumican binds to MMP-14 with moderate affinity, the strength of this interaction is between the affinity of MMP-14 and its biological inhibitor TIMP-2 (KD 56.1 nM), which forms a complex with MMP-14 and TIMP-1 (KD $\sim 1530 \mathrm{nM}$ ), which does not form a tight-binding complex with MMP-14 [27]. On the other hand, MMP-14 may be considered as a potential cell surface receptor for lumican, since its binding affinity to this metalloproteinase was similar to its binding affinity to the $\alpha 2$ integrin subunit (KD 200 nM) [28].

The MT-Loop of MMP-14 is a potential exosite target region to develop selective MMP-14 inhibitors [29] and is an interface for molecular interactions that mediate enzyme localization to $\beta 1$-integrin-rich cell adhesion complexes and regulate MMP-14 functions. In the present study, the role of the MT loop was investigated further to decipher these molecular mechanisms of interaction between MMP-14 and SLRP peptides.

Modeling their interaction might help in visualizing and obtaining a better understanding of the SLRP substrate specificity of the cleavage by MMP-14 but also in the specific regulation of MMP-14 activity by SLRPs [30,31]. 
Lumican and its derived peptides were previously shown to decrease melanoma progression $[19,32,33]$. Lumican was also reported to decrease cell proliferation in osteosarcoma [34], to inhibit cell invasion in prostate cancer [35] and in breast cancer [36-40]. However, lumican was also shown to actually facilitate cancer growth. For instance, lumican was shown to be overexpressed in lung cancer cells and has been implicated in the pathogenesis of tumorigenesis and regulation of cancer cell invasion. The expression level of lumican in cancer cells of lung adenocarcinomas was positively correlated with pleural invasion and larger tumor size [41]. More recently, the downregulation of lumican was demonstrated to extend the doubling time of cells and to delay cell growth [42]. Similarly, a significant association between lumican expression and invasive potential in gastric cancer was observed. Lumican was suggested to represent an independent prognostic factor [43]. In the same manner, lumican knockdown was shown to inhibit proliferation and migration in bladder cancer [44]. It was described to be a potential biomarker in bladder cancer [45]. Lumican expression was also shown to be positively correlated with the differentiation of osteosarcoma $[34,46]$. In addition, lumican was recently demonstrated to facilitate chondrosarcoma cell growth through an IGF-IR/ERK1/2/p53 signaling cascade [47]. These differences in the effect of lumican are closely related to the heterogeneity of its structure [19]. Lumican's structure might differ from one tissue to another. It is known that lumican is expressed as a keratan sulfate proteoglycan (KSPG) in cornea and cartilage but as a glycoprotein of $57 \mathrm{kDa}$ in skin. This heterogeneity of the lumican structure is associated with opposite regulation of cell migration. For example, lumican is able to stimulate the migration of keratocytes while it inhibits the migration of melanocytes [19]. Interestingly, the post-translational modifications of lumican are correlated with differential regulation of MMP-14 activity [26]. Lumican ( $57 \mathrm{kDa}$ ) is able to inhibit MMP-14 activity and to protect collagen degradation contributing to attenuation of MMP-14-dependent cancer cell migration and invasion [26].

Our group has demonstrated the inhibitory effect of lumican on melanoma progression $[19,30]$. In addition, previous work from the laboratory has shown that the anti-tumor effects of lumican on murine and human cell lines are mediated through interaction with the $\alpha 2 \beta 1$ integrin receptor [28].

In parallel, the team was able to highlight a minimal active sequence of the protein having anti-tumor effects similar to those of the total protein [48]. At the Leucine-Rich Repeat (LRR) 9, a 17-residue sequence, called lumcorin (SSLVELDLSYNKLKNIP), is capable of inhibiting the proliferation and migration of melanoma cells [48]. In addition, lumcorin inhibits the expression and activity of MMP-14 similarly to the glycosylated lumican. The minimal sequence mimicking the lumcorin effect could be reduced to 10 residues, ELDLSYNKLK, to give a peptide named L9M. This peptide presents inhibitory effects on MMP-14 activity in vitro [32].

It was shown that a peptide designed from the C-terminal amino acids of lumican (LumC13 or Lumikine) binds to ALK5/TGF $\beta$ R1 (type 1 receptor of TGF $\beta$ ) to promote wound healing [49]. In addition, the mechanism by which this synthetic C-terminal Lumikine binds to ALK5 was evaluated. These authors showed that Lumikine derivatives were able to promote corneal epithelial cell migration and corneal wound healing, respectively. Moreover, a computational approach allowed them to design inhibitory peptides based on the interactions of the receptor and ligands [50].

In the present study, molecular modeling was used in order to characterize, at the atomic scale, the interactions between lumican-derived peptides and MMP-14. Key residues, specific from the interaction between the inhibitory peptides and the MMP-14 protein were identified and our data allowed us to validate a methodology of identification of lumican-derived peptides, which could potentially replicate the effects of biologically known inhibitory peptides on the activity of MMP-14. 


\section{Materials and Methods}

\subsection{Selection of the Investigated Peptides}

The peptides derived from lumican used in this study were the following: lumcorin, the peptide corresponding to the LRR9 motif of lumican (SSLVELDLSYNKLKNIP); L9M, the 10 amino acid peptide from lumcorin's central part (ELDLSYNKLK); L9Mc, the cyclic L9M peptide obtained by the creation of a disulfide bond between additional terminal cysteines; and the scrambled (SCR) peptides (lumcorin SCR-LPSVSILEKLYNNLSKD, L9M SCR-SLELDLNKYK, L9Mc SCR-CSLELDLNKYKC). All peptides were soluble in basal medium. All synthetic peptides were obtained from Genscript (Piscataway, USA). In all experiments, the peptides were used at $100 \mu \mathrm{M}$. In addition, peptides derived from two other analogous SLRPs were tested through the in silico protocol designed in this study. The sequence of D9M and F9M was designed based on a sequence alignment performed between human lumican, decorin, and fibromodulin (see Figure 1).

Lumican
Fibromodulin
Decorin
Lumican
Fibromodulin
Decorin
Lumican
Fibromodulin
Decorin

Lumican
Fibromodulin
Decorin

Lumican
Fibromodulin
Decorin

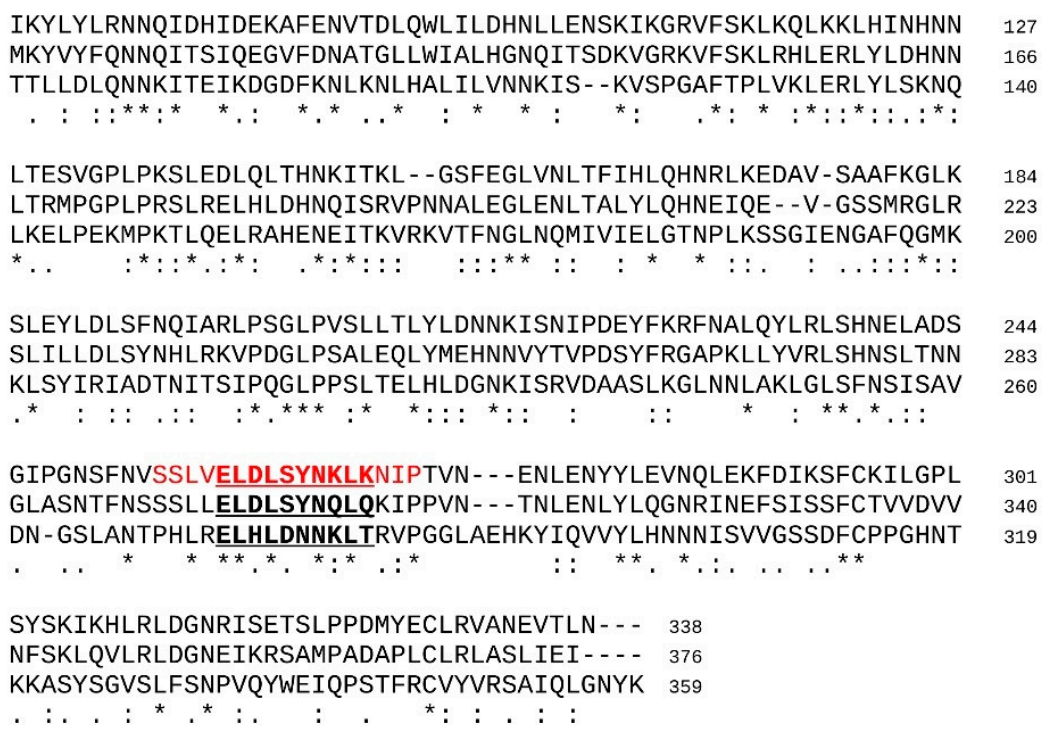

Figure 1. Sequence alignment of lumican, decorin and fibromodulin. The lumcorin peptide is evidenced in red in the lumican amino acid (aa) sequence and the L9M peptide is highlighted in red bold underlined characters. The equivalent D9M and F9M peptides in decorin and fibromodulin aa sequences are highlighted in bold underlined characters, respectively. Alignment ruler: *, identity; homology; similarity.

Each 10 amino acid sequence is the equivalent of the LRR9 motif of L9M extracted from lumcorin. Table 1 presents the sequences as well as the known biological associated effects of the peptides used for the in silico investigations and the in vitro and/or in vivo biological experiments.

Table 1. Peptide sequences considered in the study.

\begin{tabular}{ccc}
\hline Peptide & Sequence & MMP-14 Activity \\
\hline Lumcorin & SSLVELDLSYNKLKNIP & Inhibitor \\
L9M & ELDLSYNKLK & Inhibitor \\
L9Mc & CELDLSYNKLKC & Unknown \\
D9M & ELHLDNNKLT & No effect \\
F9M & ELDLSYNQLQ & No effect \\
\hline
\end{tabular}

\subsection{Design of the In Silico Protocol}

Due to the diversity of the size of the considered peptides, ranging from 10 to 17 amino acids, we decided to characterize in silico the interaction between MMP-14 and SLRPderived peptides through rigid/rigid docking techniques. Indeed, the use of regular 
ligand/protein docking software, such as Autodock4.2 [51] or Autodock Vina [52], was hindered or could be impaired by the high number of degrees of freedom generated by the backbone and sidechains (in the case of Autodock, the number of degrees of freedom ranging from 44 for D9M or F9M to 72 for lumcorin was much higher than the limit considered as acceptable, e.g., 32). In order to overcome this problem, as illustrated in Figure 2, in the present work, the following sequence of simulation steps were performed:

(i) Molecular dynamics simulations were performed in explicit solvent (see description hereafter) and allowed the conformational sampling of the energy landscape of the considered peptides.

(ii) A clustering analysis was performed with an optimized cut off with which 1 to 5 major conformations could be extracted.

(iii) Docking experiments were performed between the peptide conformations selected in step (ii) and the catalytic domain of MMP-14.

(iv) The SLRP peptides/MMP-14 complexes were analyzed, first to identify the contact and interactions interfaces and secondly to statistically characterize the MMP-14 residues implicated in the formation of the complexes.
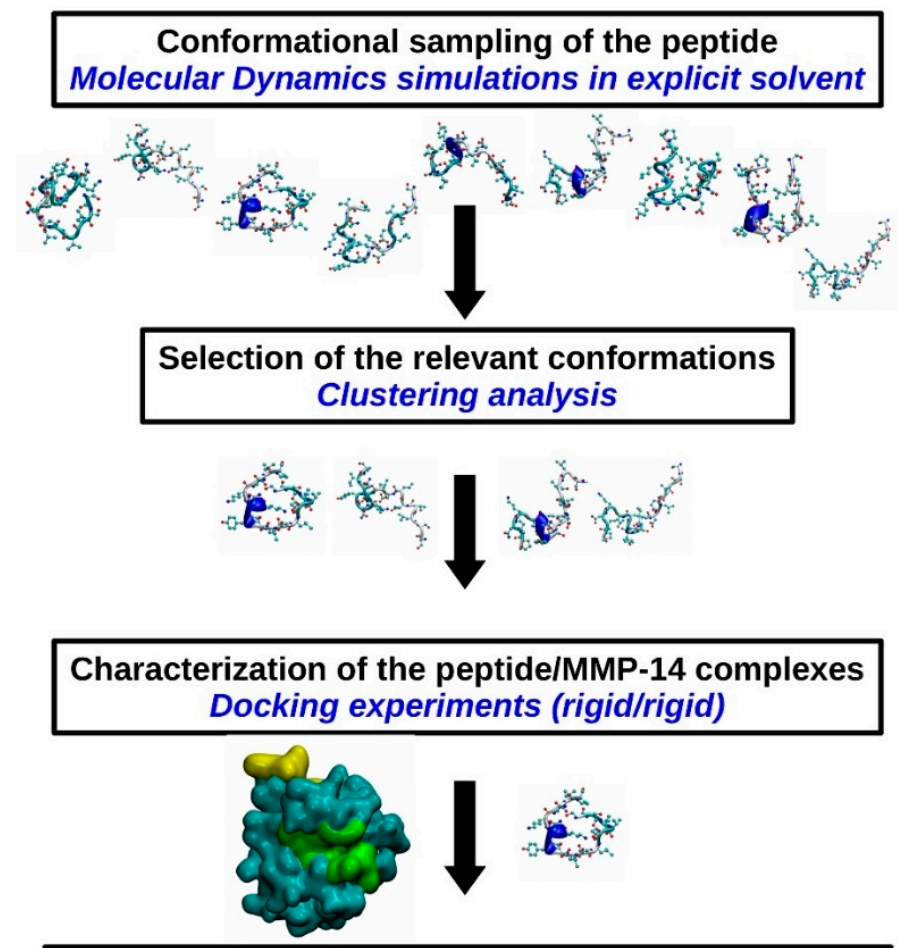

\begin{tabular}{|l|}
\hline Identification of the contacts and interactions zones \\
Statistical treatment of the docking experiments
\end{tabular}

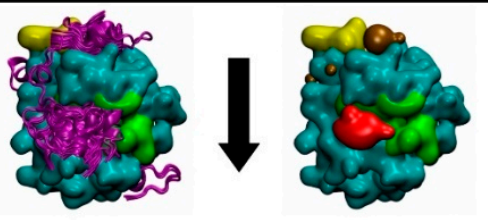

Prediction of the peptide biological activity

Figure 2. Scheme of the strategy used to decipher and predict the interaction between SLRP-derived peptides and the catalytic domain of MMP-14. The workflow designed for the present study is a 4-step process: (i) the intrinsic flexibility of the peptides is explored through classical MD simulations, (ii) the most relevant conformations are selected using clustering analysis, (iii) peptide/MMP-14 complexes are determined using a rigid/rigid docking software, and finally (iv) contacts and interactions areas are statistically characterized. 
Steps (i) and (ii) ensured the indirect consideration of the intrinsic flexibility of the peptides.

Detailed information related to each step is given in the following paragraphs.

\subsection{Molecular Dynamics Simulations}

For each peptide presented in Table 1, molecular dynamics (MD) simulations were performed in order to determine the best conformations to be used for simulations of molecular docking. Simulations were setup with GROMACS [53] and run for $100 \mathrm{~ns}$. The clustering tool of the GROMACS package was used in order to group the 10,000 conformations of each trajectory into different classes, using the gromos algorithm and an adaptative cut off ranging from 2.2 to $2.8 \AA$. To each class, a percentage of the total population was assigned, and then the number of conformations was chosen to be used in the docking experiments. The flexibility of the peptide was thus indirectly taken into account by considering different conformations in rigid protein/protein docking experiments. The GROMACS simulation package $[54,55]$ was used to perform molecular dynamics simulations focusing on each investigated peptide. The values of the energy parameters associated with the description of atoms and their interactions belonged to the OPLSAA force field [56,57]. Depending on their size, the isolated peptides were placed in boxes with side lengths varying from 40 to $190 \AA$, ensuring that a given peptide would not interact with its images when the periodic boundary conditions were applied. Prior to the production phase of the simulations, water (TIP3P model [58]) and $\mathrm{Cl}$ counter ions were added in the boxes and 5000 steps of energy minimization were performed using the steepest descent algorithm in order to relax the structures. The equilibration of the systems was operated at a temperature of $310 \mathrm{~K}$ and for $500 \mathrm{ps}$ in the isothermal-isobaric ensemble. Then, MD simulations were carried out for $100 \mathrm{~ns}$ in the NPT ensemble (pressure of 1 bar controlled by the Berendsen algorithm, and temperature of $310 \mathrm{~K}$ controlled by the V-rescale algorithm). The SHAKE algorithm [59] was used in order to freeze the length of the bonds involving hydrogen atoms. This also made it possible to integrate the equation from classical mechanics with the Verlet algorithm and an integration step of 2 fs. The Particle Mesh Ewald (PME) algorithm [60,61] was used to compute the coulombic interactions (cut off at $1.8 \mathrm{~nm}$ ), and the van der Waals interactions were evaluated with a potential-shifting function (shift applied at $1.3 \mathrm{~nm}$ and cut off applied at $1.4 \mathrm{~nm}$ ).

\subsection{Rigid Peptide-Protein Docking Experiments}

The Hex software [62] was used to perform the docking experiments. Hex was submitted to the CAPRI test, which is used to validate a docking method on known/characterized molecular complexes [63]. The configurable parameters of Hex were tuned based on the re-docking experiment: TIMP-2 was docked on MMP-14 and the solutions were compared to the crystallographic reference (PDB code $=1 B Q Q$ [64]) through the evaluation of the RMSD between the crystallographic structure and the best solution provided by the docking experiments. All docking results presented in this paper were obtained with the surface correlation method, the OPLS electrostatic potential, and the (bumps + OPLS) post processing protocol.

\subsection{Identification of the Contact and Statistical Analysis}

The Hex program provided the 100 best solutions according to an energy criterion. Each position of these solutions could be represented by the center of gravity of each peptide. The ensemble of the solutions could then be represented by 100 coordinate triplets corresponding to the positions of the centers of gravity of all the solutions. These triplets were grouped into clusters using the PAM (Partition Around Medoids) method [65]. This algorithm allowed us to associate to each cluster with the different structures of the peptides populating it. Each cluster could be located on the surface of MMP-14 and then the appropriate MMP-14 regions of interest could be identified.

The interactions between MMP-14 and the peptides were studied with the help of the CONTACT program (which is part of the CCP4 suite [66]). Contacts were then 
identified when a distance between two atoms of different residues was lower than $4 \AA$. Focusing on a region of interest, contacts with MMP-14 could be compared in a pairwise manner and relevant/interesting residues from this region could be retrieved by statistically comparing the average number of contacts and their deviation. The pairwise comparison was established using a statistical Student's t-test with a $p$-value lower than $5 \%$.

\subsection{MMP-14 Activity Assay}

The MMP-14 activity was measured in 96-well plates using a $1 \mu \mathrm{M}$ substrate: 5FAM/QXLTM520 FRET peptide in the reaction buffer supplied in the SensoLyteR520 MMP-14 Assay Kit (AnaSpec, San Jose, CA, USA). Before all activity assays, MMP-14 was activated using $1 \mathrm{mM} 4$-aminophenylmercuric acetate (APMA) for $2 \mathrm{~h}$ at $37^{\circ} \mathrm{C}$. The assays were carried out in triplicate at $37^{\circ} \mathrm{C}$. Fluorescence was measured with a spectrofluorometer (Mithras LB940, Berthold Technologies, Thoiry, France). To determine the direct effect of lumican and decorin on MMP-14 activity in vitro, the recombinant catalytic domain of human MMP-14 (5nM) (amino acids 89-265, Merck Millipore, Nottingham, UK) was preincubated at $37^{\circ} \mathrm{C}$ overnight before assay with recombinant human glycosylated lumican or glycosylated decorin (100 nM each). Lumican-derived peptides' effect on the recombinant catalytic domain of human MMP-14 (Merck) was determined by overnight pre-incubation with $100 \mu \mathrm{M}$ lumican-derived peptides (lumcorin or L9Mc) or their corresponding SCR peptides. The measurement of the hydrolysis of the fluorogenic substrate was monitored after $2 \mathrm{~h}$ of incubation at $37^{\circ} \mathrm{C}$. Results were obtained from three independent experiments.

\subsection{Cell Culture}

Murine B16F1 (CRL-6323 ${ }^{\mathrm{TM}}$ ) and human HT-144 (HTB-63) melanoma cells were obtained from ATCC. B16F1 and HT-144 melanoma cells were cultured in standard conditions in DMEM and McCoy's 5A media, respectively [67]. In all experiments, cell viability was greater than $95 \%$, as assessed by the trypan blue exclusion test.

\subsection{Migration Assay}

Migration assays of B16F1 murine melanoma cells were performed using cultureinserts (ibidi, Biovalley, Marne-la-Vallée, France). Cells were seeded on 24-well plates in culture inserts with $3 \times 10^{4}$ cells per chamber in $70 \mu \mathrm{L}$ of complete cell culture medium. After $24 \mathrm{~h}$ of incubation at $37^{\circ} \mathrm{C}$, the culture inserts were removed, cells were rinsed with Phosphate Buffer Saline (PBS), and the wells were filled with $1 \mathrm{~mL}$ of serum-free cell culture medium supplemented with $100 \mu \mathrm{M}$ lumican-derived peptide (L9Mc) or its corresponding SCR peptides. Cell motility was followed and quantified as previously described [32].

For migration assays of HT-144 human melanoma cells, Transwell ${ }^{\circledR}$ polycarbonate membranes ( $8 \mu \mathrm{m}$ pore size, $6.5 \mathrm{~mm}$ diameter) (Costar, Fisher Scientifique Labosi, Elancourt, France) were used. HT-144 cells and $4 \times 10^{4}$ in $100 \mu \mathrm{L}$ of McCoy's 5A were added to the upper chamber. The lower chamber contained $800 \mu \mathrm{L}$ of medium with $5 \%$ FBS. The medium contained mitomycin $(5 \mu \mathrm{g} / \mathrm{mL}$ ) and either no peptide (control) or $100 \mu \mathrm{M}$ lumican-derived peptide (L9Mc) or its corresponding SCR peptides. After incubation for $24 \mathrm{~h}$ at $37^{\circ} \mathrm{C}$, cells were fixed with ethanol for $20 \mathrm{~min}$ and stained with $0.1 \%$ crystal violet for $20 \mathrm{~min}$. Cells in the upper chamber were removed by cotton swab. Migrated cells were counted in the entire surface of the filter at $4 \times$ magnification under a microscope (EVOS XL core, LifeTechnologies, 91941 Courtaboeuf (Villebon Cedex), France) for every filter (3 filters per condition). Each assay was performed twice.

\subsection{Proliferation Assay}

Cell growth of B16F1 and HT-144 melanoma cells was determined using the MTT test on 96-well plates for $10^{4}$ cells/well [67]. Cells were grown for 24, 48, and $72 \mathrm{~h}$ in the presence of $100 \mu \mathrm{M}$ L9Mc or its corresponding SCR peptide. Cell growth was then analyzed using 3-[4,5-dimethylthiazol-2-yl]-2,5 diphenyltetrazolium bromide (MTT, Sigma). For this purpose, cells were incubated with culture medium supplemented with $0.5 \mathrm{mg} / \mathrm{mL}$ MTT 
for $3 \mathrm{~h}$ at $37^{\circ} \mathrm{C}$. MTT solution was then replaced by DMSO, and absorbance was measured at $560 \mathrm{~nm}$ for B16F1 and HT-144 cell proliferation. Each assay was performed twice.

\subsection{Primary Tumor Growth Analysis}

Twelve-week-old wild-type C57BL/6J female mice were subcutaneously injected in the right flank with $10^{5} \mathrm{~B} 16 \mathrm{~F} 1$ cells in the suspension of $100 \mu \mathrm{L}$ of Dulbecco's modified eagle's medium (DMEM) without or with $200 \mu \mathrm{g}$ of appropriate peptide (control mice $n=10$, L9Mc $n=10$ and L9Mc SCR $n=10$ ). Three injections of $100 \mu \mathrm{L}$ of cell culture medium with $200 \mu \mathrm{g}$ of appropriate peptide were done at day 6, 9, and 13 in the peri-tumoral area. Mice were evaluated for tumor-sizes at day $6,9,12,13,14,15$, and 16 from the initial cell injection. On day 16, mice were sacrificed, and tumors were isolated for further analysis. Tumor volume was calculated (in $\mathrm{cm}^{3}$ ) using the formula: volume $=\mathrm{a} \times \mathrm{b}^{2} \times 0.5$, where $\mathrm{a}$ is the longest diameter and $b$ the shortest [67].

This study was performed in compliance with The French Animal Welfare Act and following "The French Board for Animal Experiments". Experiments were conducted under the approval of the French "Ministère de 1'Enseignement Supérieur et de la Recherche" (ethics committee C2EA-56) in compliance with the "Directive 2010/63/UE" APAFIS\#17470$2018110911091242 \mathrm{v} 2$.

\subsection{Statistical Analysis of Biological Assays}

For proliferation, migration, and MMP-14 activity assays as well as primary tumor growth analysis, the pairwise comparison was established using a statistical student's $t$-test with a $p$-value lower than $5 \%$.

\section{Results and Discussion}

\subsection{Molecular Dynamics Simulations}

As expected for short peptides, all five investigated SLRP-derived peptides presented a finely tuned dynamic equilibrium between various conformations. Nevertheless, the analysis of the 10,000 extracted snapshots allowed the computation of the average contents in the secondary structure and this analysis gave the following classification from the most structured to the less structured peptide: F9M (25.3\%), L9M (24.8\%), L9Mc (21.1\%), lumcorin $(18.5 \%)$, and D9M (14.7\%). Considering the small discrepancies in the averages, from the local secondary structure point of view, the five peptides can be considered as equivalent.

As illustrated in Figure 3 for lumcorin peptide, the five first conformations extracted from the MD simulation all present some coil and turn secondary structures. For three of the clusters (first, second, and fourth), some helical secondary structures can be observed. Among the clusters and their representative conformations extracted from the MD simulations, only the ones corresponding to a minimum population threshold were kept for the next step of the workflow, consisting in the docking experiments. As presented in Table 2, for each peptide derived from lumican (lumcorin, L9M and L9Mc), a single conformation was used in the docking experiments, whereas for the peptides derived from decorin (D9M) and fibromodulin (F9M), five and two conformations were used, respectively.
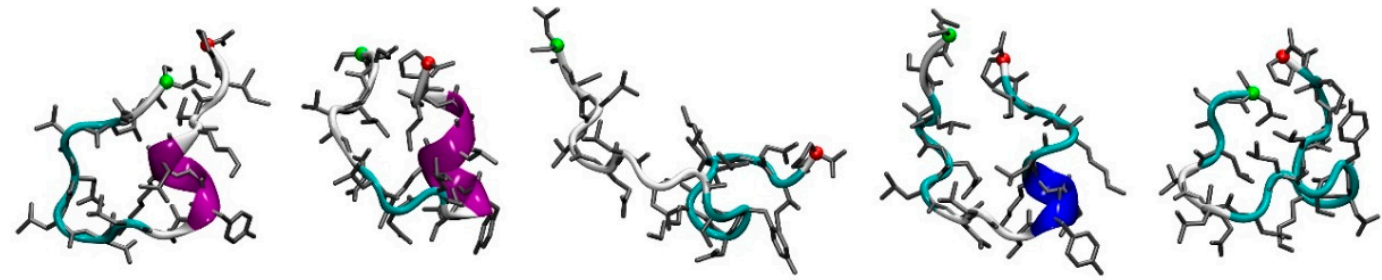

Figure 3. Representative structures of lumcorin peptides. From left to right, the first five conformations of lumcorin, extracted from MD simulations, are presented using cartoon and licorice representations. The green and red spheres represent the first and last alpha carbon of lumcorin, respectively. 
Table 2. Selection of the conformations for docking experiments.

\begin{tabular}{cc}
\hline Peptide & Number of Clusters \\
\hline Lumcorin & 1 \\
L9M & 1 \\
L9Mc & 1 \\
D9M & 5 \\
F9M & 2 \\
\hline Number of relevant conformations obtained using the g_cluster module of Gromacs for each of the simulated peptides.
\end{tabular}

\subsection{Molecular Docking}

The protocol described previously in the materials and methods section highlights, as depicted on Figure 4, two regions of interest in terms of MMP-14/peptides interaction: the catalytic zone (colored in green in Figure 4) and the MT-Loop (colored in yellow in Figure 4). In addition, on the five panels of Figure 4, the centers of mass of the 100 docked peptides are represented as colored van der Waals spheres with respect to the region they belong to (red for peptides in the vicinity of the catalytic zone and brown in the vicinity of the MT-Loop) and the associated numbers give their respective percentage of the total population. For all the peptides, considering the two highlighted areas of MMP-14, more than $70 \%$ of the total number of docking solutions are encompassed. In addition, for all cases, except the L9Mc, the catalytic zone of MMP-14 is the one that is mostly in contact with the peptide, with at least $44 \%$ of the docking solutions in the case of D9M's first conformation and at most $86 \%$ of the docking solutions in the case of F9M's first conformation. The 100 best docking solutions of the L9Mc peptide on MMP-14 stand apart from the 4 other sets of solutions obtained with the other peptides since the MT-Loop is the area of MMP-14 that is mostly in contact with the cyclic peptide.

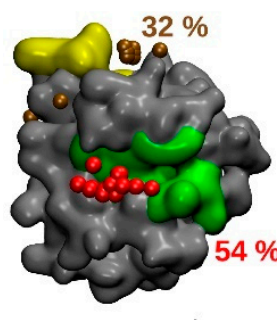

Lumcorin

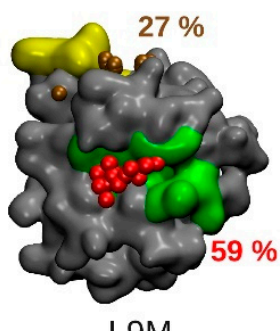

L9M

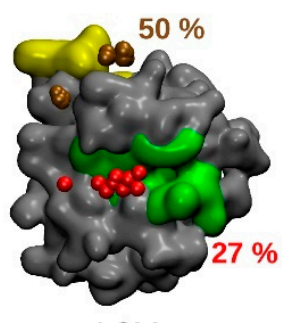

L9Mc

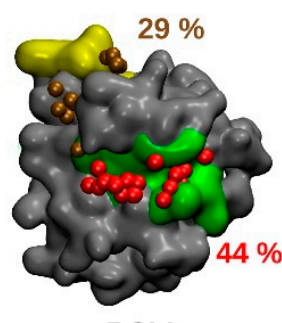

D9M

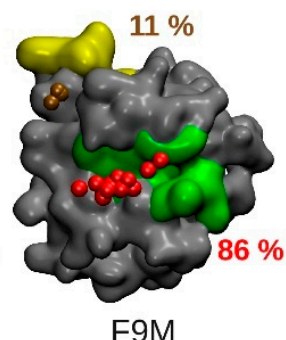

F9M

Figure 4. Anchoring of peptides on catalytic and MT-Loop regions. From left to right, localization of lumcorin, L9M, L9Mc, D9M, and F9M peptides on the MMP-14 surface. Two regions of the MMP-14 proteins are prone to interactions: the catalytic region, depicted in green, and the MT-Loop region depicted in yellow. Spheres are used to place the center of mass of the 100 best solutions and the color code indicates their localization at the surface of MMP-14: red spheres are in the catalytic region and spheres in brown are in the vicinity of the MT-Loop. The colored numbers indicate the percentages of solutions associated with each region.

The total energies associated with the best poses of the SLRP-derived peptides on MMP-14 are presented in Table 3. While lumcorin/MMP-14 and L9M/MMP-14 complexes display similar total energies ( -486 and $-462 \mathrm{kcal} / \mathrm{mol}$, respectively), D9M/MMP-14 and F9M/MMP-14 complexes display higher total energies $(-435$ and $-372 \mathrm{kcal} / \mathrm{mol}$, respectively), thus reflecting less favorable complexes and correlating the fact that the peptides derived from decorin and fibromodulin are inactive with respect to MMP-14 activity. The total energy of the best pose of the L9Mc/MMP- 14 complex $(-447 \mathrm{kcal} / \mathrm{mol})$ does not allow us to state with certainty about the inhibitory effect of L9Mc since this value can be considered as similar to the value of L9M or D9M. 
Table 3. Comparison of the total energy of the best poses.

\begin{tabular}{cc}
\hline Peptide & Total Energy (kcal/mol) \\
\hline Lumcorin & -486 \\
L9M & -462 \\
L9Mc & -447 \\
D9M & -435 \\
F9M & -372 \\
\hline
\end{tabular}

Bold numbers correspond to values averaged over the different relevant conformations.

\subsection{Statistical Treatment of the Interaction and Characterization of the Contacts}

Based on the results presented in Figure 4, we decided to thoroughly analyze the docking results corresponding to peptides located in the catalytic zone. For each residue belonging to this zone (196G, 197G, 198F, 199L, 200A, 201H, 202A, 203Y, 236V, 239H, 240E, $243 \mathrm{H}, 259 \mathrm{P}, 260 \mathrm{~F}$, and $261 \mathrm{Y}$ ) and over the 100 structures of lower energies obtained from the docking experiments, the average number of interactions (and the associated standard deviation) made between this residue and the peptide was evaluated (see Figure 5). In order to calibrate the methodology, the interactions made by the peptides, whose activity towards MMP-14 was experimentally known, were compared in a pairwise manner. The set of peptides constituted lumcorin, L9M, D9M, and F9M. The average number of contacts was compared, and significant differences were searched for using statistical Student's $t$-test with a $p$-value lower than $5 \%$. The pairwise analyses between lumcorin, L9M, D9M, and F9M (see Table 4) show that the specific contacts made with inhibitory peptides are not random. Indeed, from the lumcorin/D9M and L9M/D9M comparisons, the contacts made with residues $201 \mathrm{H}, 202 \mathrm{~A}$, and 203Y are highlighted; in parallel, from the lumcorin/F9M and L9M/F9M comparisons, the contacts made with residues 197G, 198F, 259P, and 260F are highlighted. Taken together, the results summarized in Table 4 suggest that the following residues (highlighted in violet on Figure 5G) are crucial in the MMP-14/SLRP-derived peptides interactions: 197G, 198F, 201H, 202A, 203Y, 259P, and 260F.
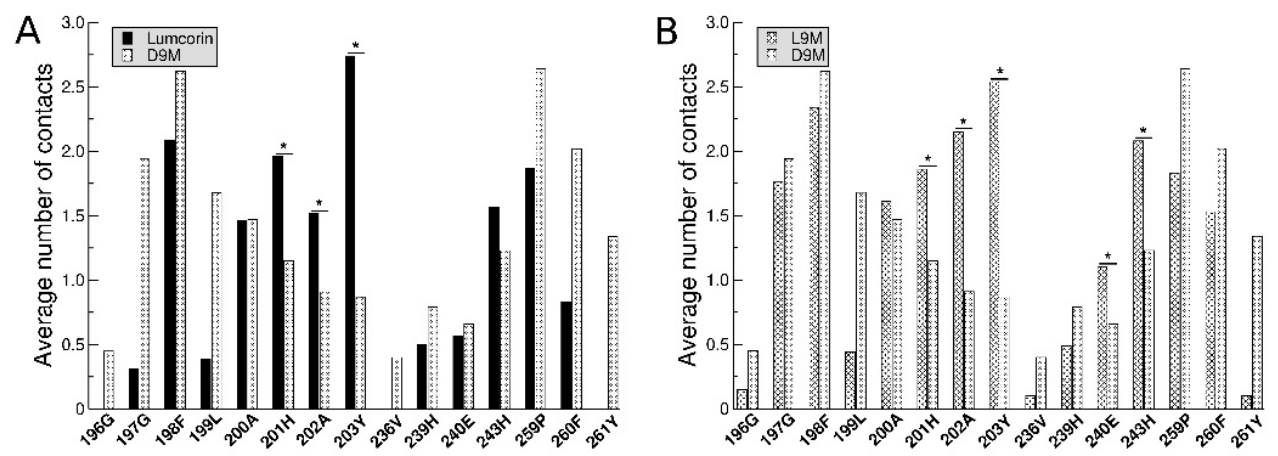

Figure 5. Cont. 

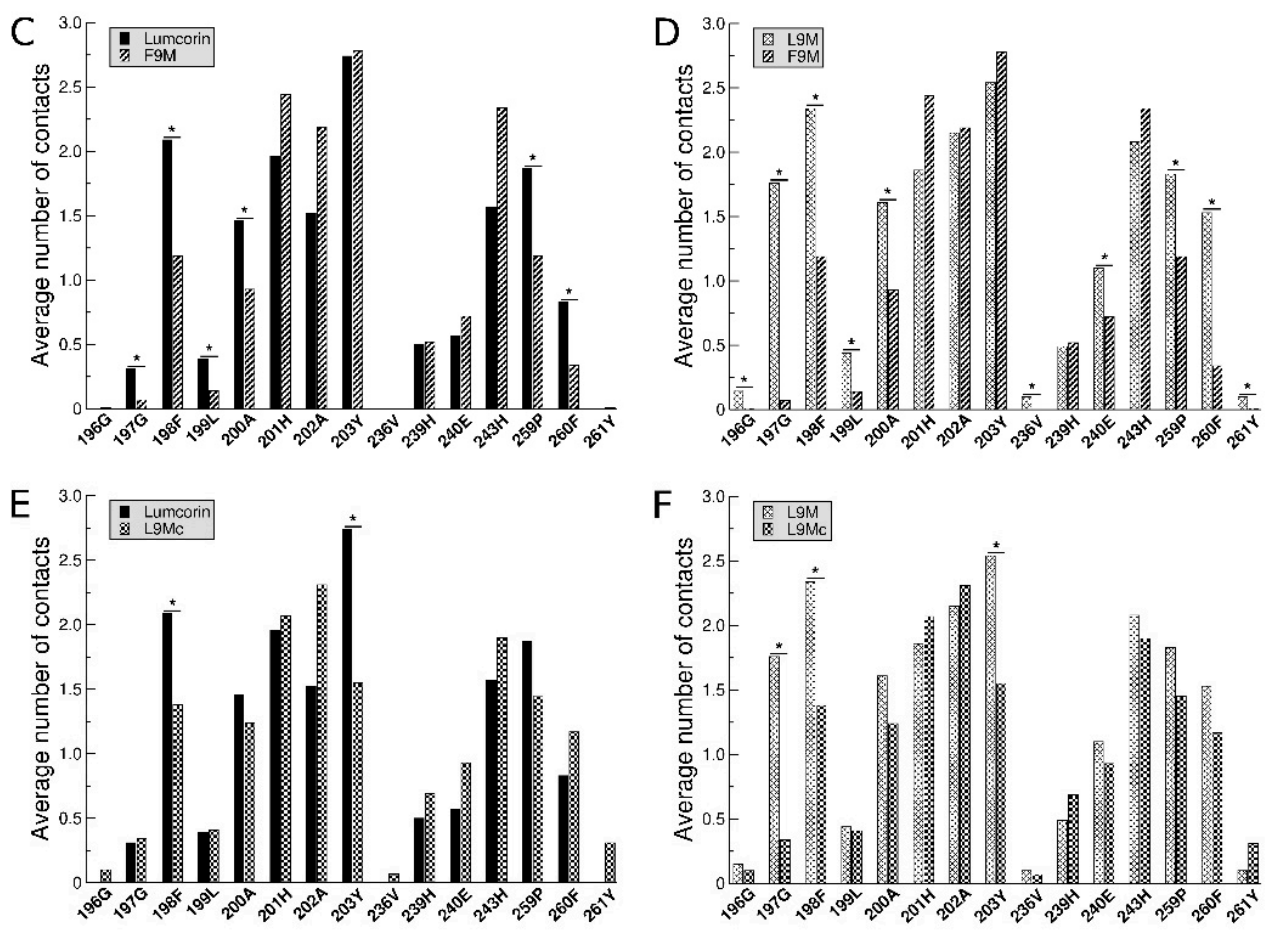

G

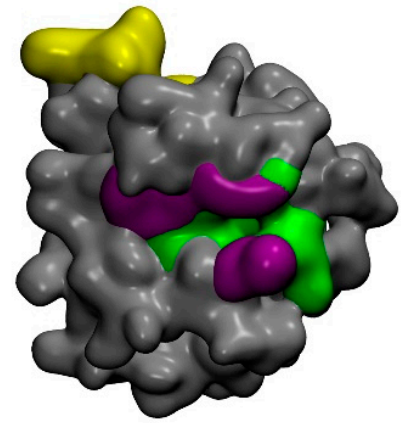

$\mathrm{H}$

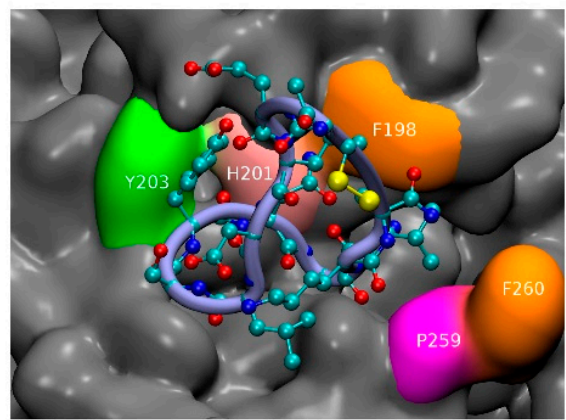

Figure 5. Pairwise comparison of the number of contacts between MMP-14 and different SLRPderived peptides. The average numbers of contacts (hydrophobic or through hydrogen bonds) and their root mean square deviations computed over the 100 dockings were evaluated for each residue of the MMP-14 catalytic region. Panels (A) to (D) correspond to the training set of the protocol since inhibitory peptides (lumcorin and L9M) are compared to inactive peptides (D9M and F9M); panels A, B, C, and D display the comparison of lumcorin and D9M, L9M and D9M, lumcorin and F9M and L9M, and F9M, respectively. In the case of D9M and F9M, for which there is more than one representative structure ( 5 for D9M and 2 for F9M) extracted by the clustering analysis, all the conformations were compared to the representative structure of lumcorin and L9M. For clarity purposes, only the comparisons with the first cluster are presented. Panels E and F display the comparison of L9Mc with lumcorin and L9M, respectively. Error bars (root mean square deviations) are not represented on the different panels but were taken into account for the comparison of the number of contacts with the Student's $t$-test. Stars identify the residues of MMP-14 displaying significant differences between the considered SLRP-derived peptide. Based on the comparison of the average number of contacts between peptides whose activity is known, key residues of the catalytic zone could be highlighted (panel G, violet surface), and docking solutions associated with L9Mc situated in the catalytic zone evidenced contacts involving some of these key residues (panel $\mathbf{H})$. , $p<0.05$. 
Table 4. Summary of the training test.

\begin{tabular}{|c|c|c|c|c|c|c|c|c|c|c|c|c|c|c|}
\hline 196 & 197 & 198 & 199 & 200 & 201 & 202 & 203 & 236 & 239 & 240 & 243 & 259 & 260 & 261 \\
\hline $\mathrm{G}$ & $\mathrm{G}$ & $\mathrm{F}$ & $\mathrm{L}$ & $\mathrm{A}$ & $\mathrm{H}$ & A & $\mathrm{Y}$ & $\mathrm{V}$ & $\mathrm{H}$ & $\mathrm{E}$ & $\mathrm{H}$ & $\mathrm{P}$ & $\mathrm{F}$ & $\mathrm{Y}$ \\
\hline \multicolumn{15}{|c|}{ Lumcorin vs. D9M } \\
\hline & & & & $\bullet$ & $\begin{array}{l}\bullet \\
\bullet \\
\bullet \\
\bullet\end{array}$ & • & $\begin{array}{l}\bullet \\
\bullet \\
\bullet \\
\bullet \\
\bullet\end{array}$ & & & & & & & \\
\hline \multicolumn{15}{|c|}{ L9M vs. D9M } \\
\hline & $\bullet$ & $\bullet$ & & • & $\begin{array}{l}\bullet \\
\bullet \\
\bullet\end{array}$ & $\begin{array}{l} \\
\bullet \\
\bullet \\
\bullet \\
\bullet\end{array}$ & $\begin{array}{l}\bullet \\
\bullet \\
\bullet \\
\bullet \\
\bullet\end{array}$ & $\bullet$ & & • & • & & $\bullet$ & \\
\hline
\end{tabular}

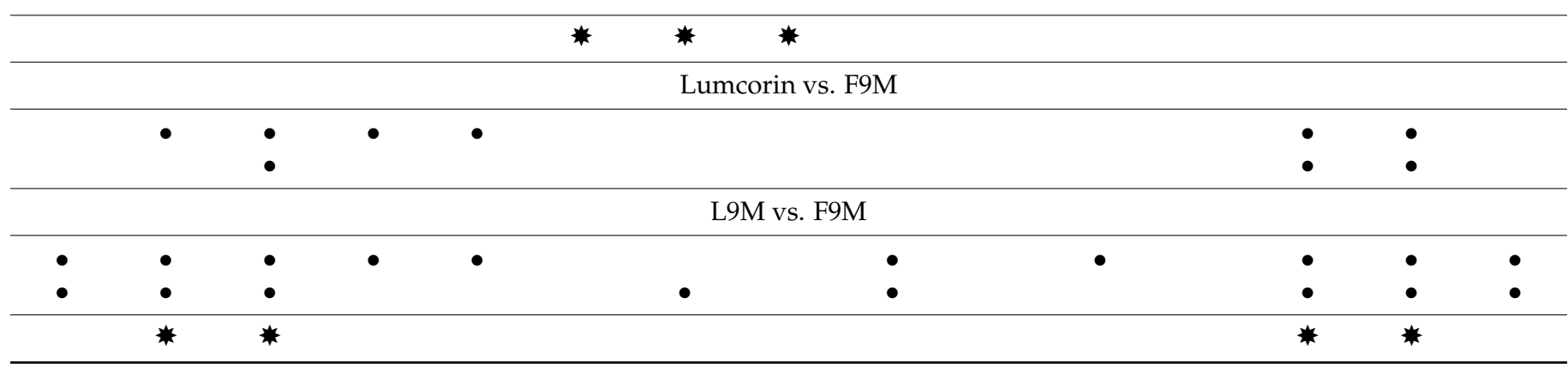

Comparison of the average number of contacts between known inhibitory peptides (lumcorin and L9M) and known unactive peptides (D9M and F9M). (•) indicates the residues of the MMP-14 catalytic zone for which the number of contacts are significantly higher for the inhibitory peptides. (*) indicates the residues that are crucial in the interaction between MMP-14 and inhibitory peptides.

\subsection{Predicting the Activity of L9M Cyclic Peptide}

L9Mc, whose activity towards MMP-14 was unknown experimentally, was compared to lumcorin and L9M. The significant differences in the average number of contacts were assessed, especially for the seven key residues highlighted and mentioned previously. From panels E and F of Figure 5, among the seven crucial residues identified through our statistical approach, only two non-adjacent residues can be highlighted as showing significant differences in the number of contacts between L9Mc and the inhibitory peptides: 198F and 203Y. Thus, L9Mc was predicted to inhibit MMP-14 activity. Figure $5 \mathrm{H}$ illustrates the contacts made by one conformation of L9Mc associated with a docking solution localized in the catalytic zone. It can be observed that five out of the seven key residues of MMP-14 are involved in the interaction with the cyclic peptide.

In order to validate our in silico protocol, it will be necessary to enrich the database of experimental results on which our strategy was built. Other potential and possible improvements could be related to the MD results. In the present study, all the conformations extracted from MD were treated the same way without taking into account the fact that a given conformation could be more or less preponderant than another. In the future, it will be necessary to weight the comparisons of the number of interactions by taking into account the population associated with the conformations. Finally, the predicting protocol was focused on the catalytic region of MMP-14, but the results presented in Figure 4 showed that the MT-Loop region could also be interesting. This could suggest that the inhibitory effects of SLRP-derived peptides could also be related to interactions taking place in this region. As such, it will be interesting to apply the same methodology to the MT-Loop region. 


\subsection{L9M Cyclic Peptide Inhibits MMP-14 Activity}

To determine the effect of L9Mc on the activity of the recombinant human catalytic domain of MMP-14, activated MMP-14 was incubated overnight with glycosylated lumican or its derived peptides (lumcorin, L9Mc) or decorin followed by measurement of the enzymatic activity. Lumican decreased MMP-14 activity by $87 \%$, lumcorin by $92 \%$, and L9Mc by 33\% (Figure 6A). The L9Mc SCR peptide had no significant effect (Figure 6A). The results of the present report confirm not only that lumican, in contrast to decorin, specifically decreases the MMP-14 activity of the catalytic domain of the enzyme, but also show that lumcorin is more efficient than L9Mc. L9Mc had no effect on MMP-2 and MMP-9 activity (data not shown).

A

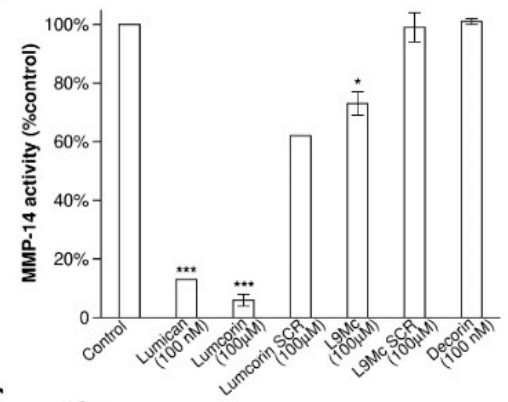

C

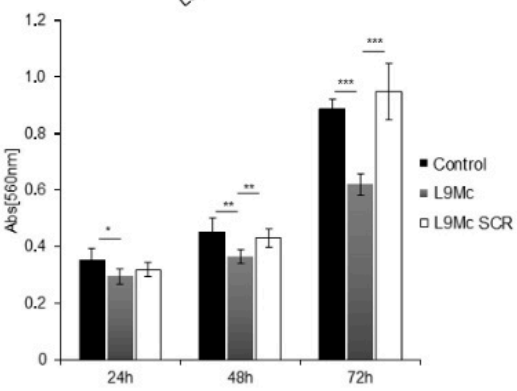

E

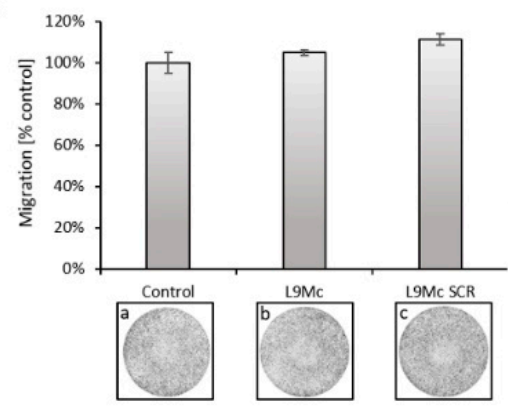

B
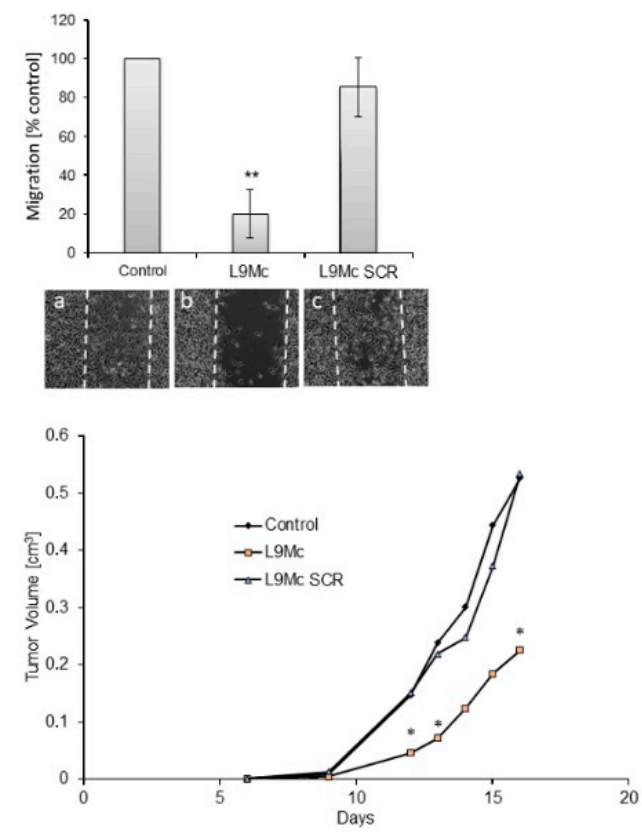

$\mathrm{F}$

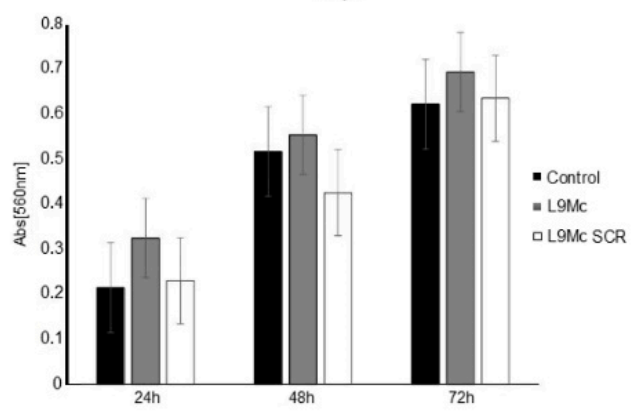

Figure 6. Effect of L9Mc on MMP-14 activity, melanoma cell migration, proliferation, and primary tumor growth. (A) MMP-14 assay. Comparison of the effects of lumican, lumcorin and its scrambled (SCR) peptide, L9Mc and its scrambled (SCR) peptide, and decorin on MMP-14 activity measured using the fluorimetric SensoLyte ${ }^{R} 520$ MMP-14 assay kit as described in the Materials and Methods. Recombinant human MMP-14 was preincubated overnight with $100 \mathrm{nM}$ lumican or $100 \mu \mathrm{M}$ lumcorin or L9Mc peptide. Data are presented as mean values \pm SD from three independent experiments. (B) Migration of B16F1 murine melanoma cells in the presence of L9Mc peptide or its control. Cells were plated on a 24-well plate, $3 \times 10^{4}$ cells per chamber of culture-insert. After $24 \mathrm{~h}$ of incubation, the culture-inserts were withdrawn, and cell migration was monitored for $48 \mathrm{~h}$ by computer-assisted phase contrast videomicroscopy. Representative images of cell positions after $48 \mathrm{~h}$ of migration in the absence of peptide (a), in the presence of $100 \mu \mathrm{M} \mathrm{L9Mc}(\mathbf{b})$, or of its SCR peptide (c) are displayed on the bottom panels. Migration was quantified as the percent of recovered area by cells. Graphs represent the mean values \pm SD calculated from 4 microscopic fields per insert. The experiment was 
done in triplicate. (C) B16F1 cell proliferation. Cells were grown for 24, 48, and $72 \mathrm{~h}$ in the absence (control) or in the presence of $100 \mu \mathrm{M}$ L9Mc or its SCR peptide. Cell growth was measured by the MTT colorimetric test at $560 \mathrm{nM}$. Results were reported as means \pm SD of sextuplicate values from three independent experiments. (D) Tumors were generated by subcutaneous injection of $10^{5} \mathrm{~B} 16 \mathrm{~F} 1$ melanoma cells in the absence of peptide (control), in the presence of $100 \mu \mathrm{M}$ L9Mc peptide, or of its scrambled (SCR) peptide. The kinetics of the melanoma tumor volume was measured as described in the Materials and Methods. *: Significant differences in tumor volume between L9Mc peptidetreated mice and control or L9Mc SCR peptide-treated mice are shown. (E) Migration of HT-144 human melanoma cells in the presence of L9Mc peptide or its control. Transwell ${ }^{\circledR}$ polycarbonate membranes ( $8 \mu \mathrm{m}$ pore size) were used. HT-144 cells and $4 \times 10^{4}$ in $100 \mu \mathrm{L}$ of McCoy's 5A were added to the upper chamber. The lower chamber contained $800 \mu \mathrm{L}$ of medium with $5 \%$ FBS. The medium contained mitomycin $(5 \mu \mathrm{g} / \mathrm{mL})$ and either no peptide (control), or $100 \mu \mathrm{M}$ lumican-derived peptide (L9Mc) or its corresponding SCR peptides. After incubation for $24 \mathrm{~h}$ at $37^{\circ} \mathrm{C}$, migrated cells were counted on the entire surface of the filter at $4 \mathrm{x}$ magnification under a microscope (EVOS XL core, LifeTechnologies) for every filter (3 filters per condition). Each assay was performed twice. Representative images of cell positions after $24 \mathrm{~h}$ of migration in the absence of peptide (a), in the presence of $100 \mu \mathrm{M} \mathrm{L9Mc} \mathrm{(b),} \mathrm{or} \mathrm{of} \mathrm{its} \mathrm{SCR} \mathrm{peptide} \mathrm{(c)} \mathrm{are} \mathrm{displayed} \mathrm{on} \mathrm{the} \mathrm{bottom} \mathrm{panels.} \mathrm{(F)} \mathrm{HT-144}$ cell proliferation. Cells were grown for 24,48 , and $72 \mathrm{~h}$ in the absence (control) or in the presence of $100 \mu \mathrm{M}$ L9Mc or its SCR peptide. Cell growth was measured by the MTT colorimetric test at $560 \mathrm{nM}$. Results are reported as means $\pm \mathrm{SD}$ of sextuplicate values from two independent experiments. *, $p<0.05{ }^{* *}, p<0.01 ;{ }^{* * *}, p<0.001$.

\subsection{L9M Cyclic Peptide Inhibits the Migration of B16F1 but Not HT-144 Melanoma Cells In Vitro}

Lumican was shown previously to inhibit cell migration [67]. Lumcorin was identified and was demonstrated to inhibit melanoma cell chemotaxis [48] and L9M was later shown to mimic the lumcorin effect in vitro [32]. To investigate whether L9Mc altered the migration of B16F1 and HT-144 cells, cell migration assay was performed. In the absence of peptide, as well as in the presence of the SCR L9Mc peptide, B16F1 cells nearly completely closed the wound after $48 \mathrm{~h}$. In contrast, L9Mc $(100 \mu \mathrm{M})$ decreased B16F1 cell migration by nearly $80 \%$ (Figure 6B) as compared to control cells. The corresponding SCR L9Mc peptide had no significant effect on cell motility. These results show that L9Mc, similarly to lumican or lumcorin or L9M [32], is able to decrease the migration of the B16F1 murine melanoma cell line in vitro. In contrast, the migration of human melanoma HT-144 cells was not significantly inhibited by L9Mc peptide $(100 \mu \mathrm{M})$ as compared to its scrambled or control cells (Figure 6E). Similar results were obtained on a second human melanoma cell line (SK-MEL-28, Figure S1A).

While the inhibitory effect of L9Mc on B16F1 cell migration has been demonstrated, its limited inhibitory effect on MMP-14 activity led us to investigate its role on cell proliferation.

\subsection{L9M Cyclic Peptide Inhibits the Proliferation of B16F1 but Not HT-144 Melanoma Cells In Vitro}

Previous studies described the anti-proliferative property of lumican [67]. Several sequences responsible for the inhibition of melanoma cell proliferation were determined [32,48]. Lumcorin and a shorter 10 amino acid peptide (linear L9M) derived from lumcorin's central part were shown to mimic the lumican effect in vitro [32]. To investigate whether the cyclic L9M peptide (L9Mc) was able to reproduce lumican's effect, the proliferation was tested in murine B16F1 melanoma cells, a tumorigenic murine melanoma cell line, and a HT-144 human metastatic cell line. After 24, 48, and $72 \mathrm{~h}$ of incubation of the cells with L9Mc, a significant inhibition of cell growth was observed in comparison to its SCR peptide or control without peptide in B16F1 cells (Figure 6C) but not in HT-144 cells (Figure 6F) and SK-MEL-28 (Figure S1B) human melanoma cell lines. After $72 \mathrm{~h}$, the inhibition of B16F1 cell growth reached $40 \%$ in the presence of L9Mc peptide (Figure 6C). 


\subsection{Effect of L9M Cyclic Peptide on Melanoma Primary Tumor Developments In Vivo}

The study of the in vivo potential inhibitory effects of L9Mc peptide was performed in C57BL/6J female mice, which were subcutaneously injected with a mix of cell suspension of the same genetic background (B16F1 melanoma cells) and L9M cyclic peptide. The tumor progression was monitored for 16 days after cell injection. The tumors were detected 9 days after cell injection. After 16 days from tumor cell injection, a $60 \%$ inhibition of tumor growth was observed, in comparison to tumors obtained in the control groups (Figure 6D).

Thus, L9Mc inhibits the proliferation of B16F1 melanoma cells in vitro and in vivo. These results suggest that L9Mc's inhibitory effect on melanoma tumor progression would be more at the cell proliferation level rather than at the cell invasion level. Indeed, the L9Mc peptide was able to inhibit melanoma cell migration but its significant inhibitory effect on MMP-14 activity was weak. MMP-14 expression has previously been shown to modulate cellular proliferation $[68,69]$. The fact that our in silico study reveals that L9Mc is more prone to interacting with the MT-Loop over the catalytic pocket might suggest that L9Mc may regulate cell proliferation via MMP-14 and its MT-Loop domain independently of MMP-14 catalytic activity. Interestingly, D'Alessio and collaborators [68] showed that TIMP-2 binding to MMP-14 rapidly activates the extracellular signal-regulated kinase $1 / 2$ (ERK1/2) pathway, which upregulates cell proliferation and migration by a mechanism independent of the proteolytic activity of MMP-14.

This result suggests that L9Mc's inhibitory effect on melanoma tumor progression would be more at the proliferation level than at the invasion level. Interestingly, in this in silico study, it was shown that the site of interaction between the domains of MMP-14 (catalytic domain or MT-Loop) and lumcorin or L9Mc are different, which might explain, at least in part, the differences between the two peptides in the inhibitory effect of MMP14 activity. Indeed, their inhibitory effect on MMP-14 appears to be inversely related to the proportion of peptide conformations interacting with the catalytic region. In vivo, L9Mc inhibits tumor development. In vitro, L9Mc inhibits the proliferation as well as the migration of $\mathrm{B} 16 \mathrm{~F} 1$ cells. These results validate the prediction of the in silico study presented above.

In the present report, L9Mc was shown to be able to inhibit melanoma cell migration. Our group recently reviewed the role of lumican, which is considered as a multivalent effector in wound healing [70]. In addition, our team previously demonstrated that lumican and lumican-derived peptides inhibit breast cancer [39,40] and melanoma cell migration $[26,32,48,67,71-73]$, which is mediated through integrin $\alpha 2 \beta 1[19,28]$ and MMP-14 interactions $[26,30,33]$.

The results on the B16F1 cell line led us to investigate the effects of L9Mc in cell migration and proliferation of the HT-144 human melanoma cell line, which expressed a relatively high amount of MMP-14 protein (see Figure S2). No significant effect of L9Mc was observed in both functional assays (Figure 6E,F). Altogether, these results suggest that further studies are necessary to better understand the discrepancies of regulation by L9Mc of cell proliferation and migration according to the different cell types and their characteristics. Different hypotheses might be postulated as described in the following part. The difference between species (mice and human cell lines) in the response to L9Mc might be explained by differences in post-translational modifications of MMP-14, such as O-glycosylation [74], in the two cell lines, leading to altered affinities of the peptides to MMP-14 either to its catalytic domain and/or to its MT-Loop domain. As a result, the activity of MMP-14 and cell migration might be differently regulated by L9Mc. In addition, the expression profile of integrin subunits $(\alpha 2, \beta 1, \alpha \mathrm{v})$, previously reported by our group as being receptors of lumican [19], was checked in the B16F1, HT-144, SK-MEL-28, and A375 cell lines (Figure S2). All cell lines expressed the $\alpha \mathrm{v}$ integrin subunit but not the $\alpha 2$ integrin subunit. Interestingly, a qualitative difference could be observed between B16F1 and HT-144 cells in the expression of the $\beta 1$ integrin subunit, suggesting a difference in the glycosylation of the $\beta 1$ integrin subunit between murine and human cells (Figure S2). This 
glycosylation alteration might interfere in the binding of lumican and its derived peptides to the $\beta 1$ integrin subunit and indirectly to MMP-14 activity.

Therefore, lumican peptides might be of interest in pharmacological applications for limiting melanoma progression; however, post-translational modifications of the receptors (integrins) and mediators (MMP-14) should be taken into account. Moreover, the computational approach presented in the present report is rapid and accurate enough to predict the preferential sites of interaction between MMPs and lumican-derived peptides, making it possible to design in silico MMP-14 inhibitors.

Our in silico approach is complementary to the computational approach used by Geistera and collaborators [50] to determine the binding modes of protein-peptide complexes and also to design TGF $\beta$ RI inhibitors. Based on a small set of experimental data, the protocol elaborated in the present study evaluates the number of contacts made by each residue in the catalytic zone of MMP-14. Although no distinction between hydrophobic nor hydrogen bonding interactions was integrated, the strength of the method was validated since its prediction of L9Mc activity towards MMP-14 was experimentally confirmed in vitro. With reasonable computational cost and effort, our method efficiently performs screening between SLRP peptides of very similar sequences. Once the selection of the relevant peptides has been achieved, the strategy proposed in [50] could then be applied to fully characterize the energetic contribution of the MMP-14 residues in the molecular complex.

\section{Conclusions}

Although similar to the linear L9M sequence, the addition of two cysteines at the Nand C-terminal end of the L9Mc peptide completely changed its conformation and might induce a lesser occupation of the catalytic zone. One of the aims of this study was to model the interactions between MMP-14 and peptides derived from lumican. Key residues were highlighted for the interaction between the inhibitory peptides and the MMP-14 protein. This study established a methodology to identify key residues of the active site of MMP-14. In the future, the experimental data will be enriched thanks to the proposals resulting from our modeling work, and will make it possible to define the interaction model between MMP-14 and its potential peptide inhibitors. Possible and feasible improvements include molecular dynamics results. In fact, for some peptides, several conformations have been used with the same importance for the comparison of the interactions whereas they are more or less predominant. It will be interesting to standardize the comparison results by the percentage of the population of each conformation used so that their weight is taken into account.

Supplementary Materials: The following are available online at https://www.mdpi.com/article/10 .3390 / cancers13194930/s1, Figure S1: Effect of L9Mc on SK-MEL-28 melanoma cell migration and proliferation, Figure S2: Profile of expression of integrin subunits $(\alpha 2, \beta 1, \alpha \mathrm{v})$ and MMP-14 in the SK-MEL-28, A375, B16F1 and HT144 cell lines analyzed by western immunoblotting.

Author Contributions: Conceptualization, S.B. (Stéphanie Baud) and S.B. (Stéphane Brézillon); methodology, J.D., K.P.-G., K.K., P.N., R.R. and N.E.; validation, S.B. (Stéphanie Baud), M.D., L.R. and S.B. (Stéphane Brézillon); formal analysis, J.D., K.P.-G., K.K., P.N., R.R., N.B., N.E., M.D., L.R., S.B. (Stéphanie Baud) and S.B. (Stéphane Brézillon); investigation, J.D., K.P.-G., K.K., P.N., R.R., N.E., N.B., M.D., L.R., S.B. (Stéphanie Baud) and S.B. (Stéphane Brézillon); resources, S.B. (Stéphanie Baud), M.D. and S.B. (Stéphane Brézillon); data curation, S.B. (Stéphanie Baud), M.D., L.R. and S.B. (Stéphane Brézillon); writing—original draft preparation, J.D., S.B. (Stéphanie Baud) and S.B. (Stéphane Brézillon); writing—review and editing, S.B. (Stéphanie Baud), N.B., M.D., L.R. and S.B. (Stéphane Brézillon); visualization, S.B. (Stéphanie Baud); supervision, S.B. (Stéphanie Baud) and S.B. (Stéphane Brézillon); project administration, S.B. (Stéphanie Baud) and S.B. (Stéphane Brézillon); funding acquisition, S.B. (Stéphanie Baud) and S.B. (Stéphane Brézillon) All authors have read and agreed to the published version of the manuscript.

Funding: This research was funded by grants from CNRS, the Universite de Reims- ChampagneArdenne, and the Ligue Contre le Cancer, Conférence de Coordination Inter Régionale du Grand Est (CCIR-GE) 30036506-UMR7369. This publication is part of the joint-PhD (University of Pa- 
tras/University of Reims Champagne Ardenne) of Konstantina Karamanou, under the Financial support of Eiffel Scholarship of Excellence (870731F), supplied from the French Ministry of Foreign Affairs, as well as General Secretariat for Research and Technology (GSRT) \& the Hellenic Foundation for Research and Innovation (HFRI).

Institutional Review Board Statement: This study was performed in compliance with the French Animal Welfare Act and following "The French Board for Animal Experiments". Experiments were conducted under approval of the French "Ministère de l'Enseignement Supérieur et de la Recherche" (ethics committee C2EA-56) in compliance with the "Directive 2010/63/UE". APAFIS\#17470$2018110911091242 \mathrm{v} 2$.

Informed Consent Statement: Not applicable.

Data Availability Statement: The data presented in this study are available on request from the corresponding author.

Acknowledgments: The authors thank the HPC-Regional Center ROMEO and the Multiscale Molecular Modeling Platform (P3M) of the University of Reims Champagne- Ardenne (France) for providing CPU time, time and support.

Conflicts of Interest: The authors declare no conflict of interest.

\section{References}

1. Maquart, F.X.; Siméon, A.; Pasco, S.; Monboisse, J.C. Regulation of cell activity by the extracellular matrix: The concept of matrikines. J. Soc. Biol. 1999, 193, 423-428. [CrossRef] [PubMed]

2. Ricard-Blum, S.; Salza, R. Matricryptins and matrikines: Biologically active fragments of the extracellular matrix. Exp. Dermatol. 2014, 23, 457-463. [CrossRef] [PubMed]

3. Ricard-Blum, S.; Vallet, S.D. Fragments generated upon extracellular matrix remodeling: Biological regulators and potential drugs. Matrix Biol. 2019, 75-76, 170-189. [CrossRef] [PubMed]

4. Seiki, M. Membrane-type matrix metalloproteinases. APMIS 1999, 107, 137-143. [CrossRef] [PubMed]

5. Nomura, H.; Sato, H.; Seiki, M.; Mai, M.; Okada, Y. Expression of membrane-type matrix metalloproteinase in human gastric carcinomas. Cancer Res. 1995, 55, 3263-3266.

6. Ueno, H.; Nakamura, H.; Inoue, M.; Imai, K.; Noguchi, M.; Sato, H.; Seiki, M.; Okada, Y. Expression and tissue localization of membrane-types 1, 2, and 3 matrix metalloproteinases in human invasive breast carcinomas. Cancer Res. 1997, 57, $2055-2060$.

7. Li, Y.; Aoki, T.; Mori, Y.; Ahmad, M.; Miyamori, H.; Takino, T.; Sato, H. Cleavage of Lumican by Membrane-Type Matrix Metalloproteinase-1 Abrogates This Proteoglycan-Mediated Suppression of Tumor Cell Colony Formation in Soft Agar. Cancer Res. 2004, 64, 7058-7064. [CrossRef]

8. Itoh, Y. Membrane-type matrix metalloproteinases: Their functions and regulations. Matrix Biol. 2015, 44-46, 207-223. [CrossRef]

9. Gifford, V.; Itoh, Y. MT1-MMP-dependent cell migration: Proteolytic and non-proteolytic mechanisms. Biochem. Soc. Trans. 2019, 47, 811-826. [CrossRef]

10. Will, H.; Atkinson, S.J.; Butler, S.G.; Smith, B.; Murphy, G. The soluble catalytic domain of membrane type 1 Matrix Metalloproteinase cleaves the propeptide of progelatinase A and initiates autoproteolytic activation regulation by TIMP-2 and TIMP-3. J. Biol Chem. 1996, 271, 17119-17123. [CrossRef] [PubMed]

11. Schaefer, L.; Iozzo, R.V. Biological Functions of the Small Leucine-rich Proteoglycans: From Genetics to Signal Transduction. J. Biol. Chem. 2008, 283, 21305-21309. [CrossRef]

12. Iozzo, R.V.; Schaefer, L. Proteoglycan form and function: A comprehensive nomenclature of proteoglycans. Matrix Biol. 2015, 42, 11-55. [CrossRef]

13. Funderburgh, J.; Mann, M.; Conrad, G. Arterial lumican. Properties of a corneal-type keratan sulfate proteoglycan from bovine aorta. J. Biol. Chem. 1991, 266, 24773-24777. [CrossRef]

14. Funderburgh, J.L.; Mitschler, R.R.; Funderburgh, M.L.; Roth, M.R.; Chapes, S.K.; Conrad, G.W. Macrophage receptors for lumican. A corneal keratan sulfate proteoglycan. Investig. Ophthalmol. Vis. Sci. 1997, 38, 1159-1167.

15. Chakravarti, S.; Magnuson, T.; Lass, J.H.; Jepsen, K.J.; LaMantia, C.; Carroll, H. Lumican Regulates Collagen Fibril Assembly: Skin Fragility and Corneal Opacity in the Absence of Lumican. J. Cell Biol. 1998, 141, 1277-1286. [CrossRef]

16. Saika, S.; Ohnishi, Y.; Ooshima, A.; Liu, C.Y.; Kao, W.W. Epithelial repair: Roles of extracellular matrix. Cornea 2020, 21, S23-S29. [CrossRef]

17. Kao, W.W.-Y.; Funderburgh, J.L.; Xia, Y.; Liu, C.-Y.; Conrad, G.W. Focus on Molecules: Lumican. Exp. Eye Res. 2006, 82, 3-4. [CrossRef]

18. Yeh, J.-T.; Yeh, L.-K.; Jung, S.-M.; Chang, T.-J.; Wu, H.-H.; Shiu, T.-F.; Liu, C.-Y.; Kao, W.-Y.; Chu, P.-H. Impaired skin wound healing in lumican-null mice. Br. J. Dermatol. 2010, 163, 1174-1180. [CrossRef] [PubMed]

19. Brézillon, S.; Pietraszek, K.; Maquart, F.X.; Wegrowski, Y. Lumican effects in the control of tumor progression and their links with metalloproteinases and integrins. FEBS J. 2013, 280, 2369-2381. [CrossRef] [PubMed] 
20. Grover, J.; Chen, X.N.; Korenberg, J.R.; Roughley, P. The human lumican gene. Organization, Chromosomal location, and expression in articular cartilage. J. Biol. Chem. 1995, 270, 21942-21949. [CrossRef] [PubMed]

21. Mimura, T.; Han, K.Y.; Onguchi, T.; Chang, J.-H.; Kim, T.-I.; Kojima, T.; Zhou, Z.; Azar, D.T. MT1-MMP-Mediated Cleavage of Decorin in Corneal Angiogenesis. J. Vasc. Res. 2009, 46, 541-550. [CrossRef] [PubMed]

22. Heathfield, T.F.; Onnerfjord, P.; Dahlberg, L.; Heinegård, D. Cleavage of Fibromodulin in Cartilage Explants Involves Removal of the N-terminal Tyrosine Sulfate-rich Region by Proteolysis at a Site That Is Sensitive to Matrix Metalloproteinase-13. J. Biol. Chem. 2004, 279, 6286-6295. [CrossRef] [PubMed]

23. Monfort, J.; Tardif, G.; Reboul, P.; Mineau, F.; Roughley, P.; Pelletier, J.-P.; Martel-Pelletier, J. Degradation of small leucine-rich repeat proteoglycans by matrix metalloprotease-13: Identification of a new biglycan cleavage site. Arthritis Res. 2006, 8, R26. [CrossRef] [PubMed]

24. Chakravarti, S.; Stallings, R.L.; SundarRaj, N.; Cornuet, P.K.; Hassell, J.R. Primary structure of human lumican (keratan sulfate proteoglycan) and localization of the gene (LUM) to chromosome 12q21.3-q22. Genomics 1995, 27, 481-488. [CrossRef]

25. McEwan, P.A.; Scott, P.G.; Bishop, P.; Bella, J. Structural correlations in the family of small leucine-rich repeat proteins and proteoglycans. J. Struct. Biol. 2006, 155, 294-305. [CrossRef] [PubMed]

26. Pietraszek-Gremplewicz, K.; Chatron-Colliet, A.; Brézillon, S.; Perreau, C.; Jakubiak-Augustyn, A.; Krotkiewski, H.; Maquart, F.-X.; Wegrowski, Y. Lumican: A new inhibitor of matrix metalloproteinase-14 activity. FEBS Lett. 2014, 588, 4319-4324. [CrossRef] [PubMed]

27. Grossman, M.; Tworowski, D.; Dym, O.; Lee, M.-H.; Levy, Y.; Murphy, G.; Sagi, I. The Intrinsic Protein Flexibility of Endogenous Protease Inhibitor TIMP-1 Controls Its Binding Interface and Affects Its Function. Biochemistry 2010, 49, 6184-6192. [CrossRef]

28. Zeltz, C.; Brézillon, S.; Käpylä, J.; Eble, J.A.; Bobichon, H.; Terryn, C.; Perreau, C.; Franz, C.M.; Heino, J.; Maquart, F.X.; et al. Lumican inhibits cell migration through $\alpha 2 \beta 1$ integrin. Exp. Cell Res. 2010, 316, 2922-2931. [CrossRef]

29. Woskowicz, A.M.; Weaver, S.A.; Shitomi, Y.; Ito, N.; Itoh, Y. MT-LOOP-dependent Localization of Membrane Type I Matrix Metalloproteinase (MT1-MMP) to the Cell Adhesion Complexes Promotes Cancer Cell Invasion. J. Biol. Chem. 2013, 288, 35126-35137. [CrossRef]

30. Pietraszek-Gremplewicz, K.; Karamanou, K.; Niang, A.; Dauchez, M.; Belloy, N.; Maquart, F.X.; Baud, S.; Brézillon, S. Small leucine-rich proteoglycans and matrix metalloproteinase-14: Key partners? Matrix Biol. 2019, 75-76, 271-285. [CrossRef]

31. Karamanos, N.; Theocharis, A.; Piperigkou, Z.; Watanabe, H.; Baud, S.; Brézillon, S.; Gotte, M.; Sanderson, R.; Passi, A.; Vigetti, D.; et al. Proteoglycans: From chemical structure diversity to multifunctional cell regulation and therapeutics. Chem. Rev. 2018, 118, 9152-9232. [CrossRef]

32. Pietraszek, K.; Brézillon, S.; Perreau, C.; Malicka-Błaszkiewicz, M.; Maquart, F.-X.; Wegrowski, Y. Lumican—Derived Peptides Inhibit Melanoma Cell Growth and Migration. PLoS ONE 2013, 8, e76232. [CrossRef]

33. Stasiak, M.; Boncela, J.; Perreau, C.; Karamanou, K.; Chatron-Colliet, A.; Proult, I.; Przygodzka, P.; Chakravarti, S.; Maquart, F.-X.; Kowalska, M.A.; et al. Lumican Inhibits SNAIL-Induced Melanoma Cell Migration Specifically by Blocking MMP-14 Activity. PLoS ONE 2016, 11, e0150226. [CrossRef]

34. Nikitovic, D.; Berdiaki, A.; Zafiropoulos, A.; Katonis, P.; Tsatsakis, A.; Karamanos, N.K.; Tzanakakis, G.N. Lumican expression is positively correlated with the differentiation and negatively with the growth of human osteosarcoma cells. FEBS J. 2007, 275, 350-361. [CrossRef]

35. Coulson-Thomas, V.J.; Coulson-Thomas, Y.M.; Gesteira, T.F.; de Paula, C.A.A.; Carneiro, C.R.; Ortiz, V.; Toma, L.; Kao, W.W.-Y.; Nader, H.B. Lumican expression, localization and antitumor activity in prostate cancer. Exp. Cell Res. 2013, 319, 967-981. [CrossRef]

36. Troup, S.; Njue, C.; Kliewer, E.V.; Parisien, M.; Roskelley, C.; Chakravarti, S.; Roughley, P.J.; Murphy, L.C.; Watson, P. Reduced expression of the small leucine-rich proteoglycans, lumican, and decorin is associated with poor outcome in node-negative invasive breast cancer. Clin. Cancer Res. 2003, 9, 207-214. [PubMed]

37. Leygue, E.; Snell, L.; Dotzlaw, H.; Hole, K.; Hiller-Hitchcock, T.; Roughley, P.J.; Watson, P.H.; Murphy, L.C. Expression of lumican in human breast carcinoma. Cancer Res. 1998, 58, 1348-1352. [PubMed]

38. Leygue, E.; Snell, L.; Dotzlaw, H.; Hole, K.; Hiller-Hitchcock, T.; Murphy, L.C.; Roughley, P.J.; Watson, P.H. Lumican and decorin are differentially expressed in human breast carcinoma. J. Pathol. 2000, 192, 313-320. [CrossRef]

39. Karamanou, K.; Franchi, M.; Piperigkou, Z.; Perreau, C.; Maquart, F.-X.; Vynios, D.H.; Brézillon, S. Lumican effectively regulates the estrogen receptors-associated functional properties of breast cancer cells, expression of matrix effectors and epithelial-tomesenchymal transition. Sci. Rep. 2017, 7, 45138. [CrossRef] [PubMed]

40. Karamanou, K.; Franchi, M.; Vynios, D.; Brézillon, S. Epithelial-to-mesenchymal transition and invadopodia markers in breast cancer: Lumican a key regulator. Semin. Cancer Biol. 2019, 62, 125-133. [CrossRef] [PubMed]

41. Naito, Z.; Matsuda, Y.; Yamamoto, T.; Kudo, M.; Kawahara, K.; Kawamoto, M.; Nakajima, Y.; Koizumi, K.; Nakazawa, N.; Ishiwata, T. Expression and roles of lumican in lung adenocarcinoma and squamous cell carcinoma. Int. J. Oncol. 1992, 33, 1177-1185. [CrossRef]

42. Yang, C.-T.; Hsu, P.-C.; Chow, S.-E. Downregulation of lumican enhanced mitotic defects and aneuploidy in lung cancer cells. Cell Cycle 2019, 19, 97-108. [CrossRef]

43. Chen, L.; Zhang, Y.; Zuo, Y.; Ma, F.; Song, H. Lumican expression in gastric cancer and its association with biological behavior and prognosis. Oncol. Lett. 2017, 14, 5235-5240. [CrossRef] 
44. Mao, W.; Luo, M.; Huang, X.; Wang, Q.; Fan, J.; Gao, L.; Zhang, Y.; Geng, J. Knockdown of Lumican Inhibits Proliferation and Migration of Bladder Cancer. Transl. Oncol. 2019, 12, 1072-1078. [CrossRef]

45. Appunni, S.; Anand, V.; Khandelwal, M.; Gupta, N.; Rubens, M.; Sharma, A. Small Leucine Rich Proteoglycans (decorin, biglycan and lumican) in cancer. Clin. Chim. Acta 2019, 491, 1-7. [CrossRef]

46. Nikitovic, D.; Chalkiadaki, G.; Berdiaki, A.; Aggelidakis, J.; Katonis, P.; Karamanos, N.; Tzanakakis, G. Lumican regulates osteosarcoma cell adhesion by modulating TGF 32 activity. Int. J. Biochem. Cell Biol. 2011, 43, 928-935. [CrossRef]

47. Papoutsidakis, A.; Giatagana, E.M.; Berdiaki, A.; Spyridaki, I.; Spandidos, D.A.; Tsatsakis, A.; Tzanakakis, G.N.; Nikitovic, D. Lumican mediates HTB94 chondrosarcoma cell growth via an IGF-IR/Erk1/2 axis. Int. J. Oncol. 2020, 57, 791-803. [CrossRef] [PubMed]

48. Zeltz, C.; Brézillon, S.; Perreau, C.; Ramont, L.; Maquart, F.-X.; Wegrowski, Y. Lumcorin: A leucine-rich repeat 9-derived peptide from human lumican inhibiting melanoma cell migration. FEBS Lett. 2009, 583, 3027-3032. [CrossRef] [PubMed]

49. Yamanaka, O.; Yuan, Y.; Coulson-Thomas, V.J.; Gesteira, T.F.; Call, M.K.; Zhang, Y.; Zhang, J.; Chang, S.-H.; Xie, C.; Liu, C.-Y.; et al. Lumican Binds ALK5 to Promote Epithelium Wound Healing. PLoS ONE 2013, 8, e82730. [CrossRef]

50. Gesteira, T.F.; Coulson-Thomas, V.J.; Yuan, Y.; Zhang, J.; Nader, H.; Kao, W.W.-Y. Lumican Peptides: Rational Design Targeting ALK5/TGFBRI. Sci. Rep. 2017, 7, 42057. [CrossRef]

51. Morris, G.; Huey, R.; Lindstrom, W.; Sanner, M.F.; Belew, R.K.; Goodsell, D.S.; Olson, A.J. AutoDock4 and AutoDockTools4: Automated docking with selective receptor flexibility. J. Comput. Chem. 2009, 30, 2785-2791. [CrossRef] [PubMed]

52. Trott, O.; Olson, A.J. AutoDock Vina: Improving the speed and accuracy of docking with a new scoring function, efficient optimization, and multithreading. J. Comput. Chem. 2009, 31, 455-461. [CrossRef] [PubMed]

53. Berendsen, H.; Van Der Spoel, D.; Van Drunen, R. GROMACS: A message-passing parallel molecular dynamics implementation. Comput. Phys. Commun. 1995, 91, 43-56. [CrossRef]

54. Lindahl, E.; Hess, B.; Van Der Spoel, D. GROMACS 3.0: A package for molecular simulation and trajectory analysis. J. Mol. Model. 2001, 7, 306-317. [CrossRef]

55. van der Spoel, D.; Lindahl, E.; Hess, B.; Groenhof, G.; Mark, A.E.; Berendsen, H.J.C. GROMACS: Fast, flexible, and free. J. Comput. Chem. 2005, 26, 1701-1718. [CrossRef]

56. Jorgensen, W.L.; Maxwell, D.S.; Tirado-Rives, J. Development and Testing of the OPLS All-Atom Force Field on Conformational Energetics and Properties of Organic Liquids. J. Am. Chem. Soc. 1996, 118, 11225-11236. [CrossRef]

57. Kaminski, G.A.; Friesner, R.A.; Tirado-Rives, J.; Jorgensen, W.L. Evaluation and Reparametrization of the OPLS-AA Force Field for Proteins via Comparison with Accurate Quantum Chemical Calculations on Peptidest. J. Phys. Chem. B 2001, 105, 6474-6487. [CrossRef]

58. Jorgensen, W.L.; Madura, J.D. Quantum and statistical mechanical studies of liquids. 25. Solvation and conformation of methanol in water. J. Am. Chem. Soc. 1983, 105, 1407-1413. [CrossRef]

59. Ryckaert, J.-P.; Ciccotti, G.; Berendsen, H.J. Numerical integration of the cartesian equations of motion of a system with constraints: Molecular dynamics of n-alkanes. J. Comput. Phys. 1977, 23, 327-341. [CrossRef]

60. Darden, T.A.; York, D.M.; Pedersen, L.G. Particle mesh Ewald: AnN·log(N) method for Ewald sums in large systems. J. Chem. Phys. 1993, 98, 10089-10092. [CrossRef]

61. Essmann, U.; Perera, L.; Berkowitz, M.; Darden, T.; Lee, H.; Pedersen, L.G. A smooth particle mesh Ewald method. J. Chem. Phys. 1995, 103, 8577-8593. [CrossRef]

62. Ritchie, D.W.; Kozakov, D.; Vajda, S. Accelerating and Focusing Protein-Protein Docking Correlations Using A Six-Dimensional Analytic FFT Generating Function. Bioinformatics. 2008, 24, 1865-1873. [CrossRef] [PubMed]

63. Ritchie, D.W. Evaluation of protein docking predictions using Hex 3.1 in CAPRI rounds 1 and 2. Proteins 2003, 52, 98-106. [CrossRef] [PubMed]

64. Fernandez-Catalan, C.; Bode, W.; Huber, R.; Turk, D.; Calvete, J.; Lichte, A.; Tschesche, H.; Maskos, K. Crystal structure of the complex formed by the membrane type 1-matrix metalloproteinase with the tissue inhibitor of metalloproteinases-2, the soluble progelatinase A receptor. EMBO J. 1998, 17, 5238-5248. [CrossRef] [PubMed]

65. Kaufman, L.; Rousseeuw, P.J. Clustering by Means of Medoids, Statistical Data Analysis Based on L1-Norm and Related Methods; Dodge North-Holland, Y., Ed.; Springer: Basel, Switzerland, 1987; pp. 405-416. Available online: https://wis.kuleuven.be/stat/robust/ papers/publications-1987/kaufmanrousseeuw-clusteringbymedoids-11norm-1987.pdf (accessed on 3 September 2021).

66. Winn, M.D.; Ballard, C.C.; Cowtan, K.D.; Dodson, E.J.; Emsley, P.; Evans, R.R.; Keegan, R.M.; Krissinel, E.B.; Leslie, A.G.; McCoy, A.; et al. Overview of the CCP4 suite and current developments. Acta Cryst. D Biol. Crystallogr. 2011, 67, 235-242. [CrossRef]

67. Vuillermoz, B.; Khoruzhenko, A.; D’Onofrio, M.F.; Ramont, L.; Venteo, L.; Perreau, C.; Antonicelli, F.; Maquart, F.X.; Wegrowski, Y. The small leucine-rich proteoglycan lumican inhibits melanoma progression. Exp. Cell Res. 2004, 296, 294-306. [CrossRef] [PubMed]

68. D’Alessio, S.; Ferrari, G.; Cinnante, K.; Scheerer, W.; Galloway, A.C.; Roses, D.F.; Rozanov, D.V.; Remacle, A.G.; Oh, E.-S.; Shiryaev, S.A.; et al. Tissue Inhibitor of Metalloproteinases-2 Binding to Membrane-type 1 Matrix Metalloproteinase Induces MAPK Activation and Cell Growth by a Non-proteolytic Mechanism. J. Biol. Chem. 2008, 283, 87-99. [CrossRef]

69. Aoki, T.; Sato, D.; Li, Y.; Takino, T.; Miyamori, H.; Sato, H. Cleavage of Apolipoprotein E by Membrane-Type Matrix Metalloproteinase-1 Abrogates Suppression of Cell Proliferation. J. Biochem. 2005, 137, 95-99. [CrossRef] 
70. Karamanou, K.; Perrot, G.; Maquart, F.-X.; Brézillon, S. Lumican as a multivalent effector in wound healing. Adv. Drug Deliv. Rev. 2018, 129, 344-351. [CrossRef]

71. Brezillon, S.; Zeltz, C.; Schneider, L.; Terryn, C.; Vuillermoz, B.; Ramont, L.; Perrau, C.; Pluot, M.; Diebold, M.D.; Radwanska, A.; et al. Lumican inhibits B16F1 melanoma cell lung metastasis. J. Physiol. Pharmacol. 2009, 60, 15-22.

72. Brézillon, S.; Radwanska, A.; Zeltz, C.; Malkowski, A.; Ploton, D.; Bobichon, H.; Perreau, C.; Malicka-Blaszkiewicz, M.; Maquart, F.-X.; Wegrowski, Y. Lumican core protein inhibits melanoma cell migration via alterations of focal adhesion complexes. Cancer Lett. 2009, 283, 92-100. [CrossRef] [PubMed]

73. Jeanne, A.; Untereiner, V.; Perreau, C.; Proult, I.; Gobinet, C.; Boulagnon-Rombi, C.; Terryn, C.; Martiny, L.; Brézillon, S.; Dedieu, S. Lumican delays melanoma growth in mice and drives tumor molecular assembly as well as response to matrix-targeted TAX2 therapeutic peptide. Sci. Rep. 2017, 7, 7700. [CrossRef] [PubMed]

74. Nguyen, A.T.; Chia, J.; Ros, M.; Hui, K.; Saltel, F.; Bard, F. Organelle Specific O-Glycosylation Drives MMP14 Activation, Tumor Growth, and Metastasis. Cancer Cell 2017, 32, 639-653. [CrossRef] [PubMed] 